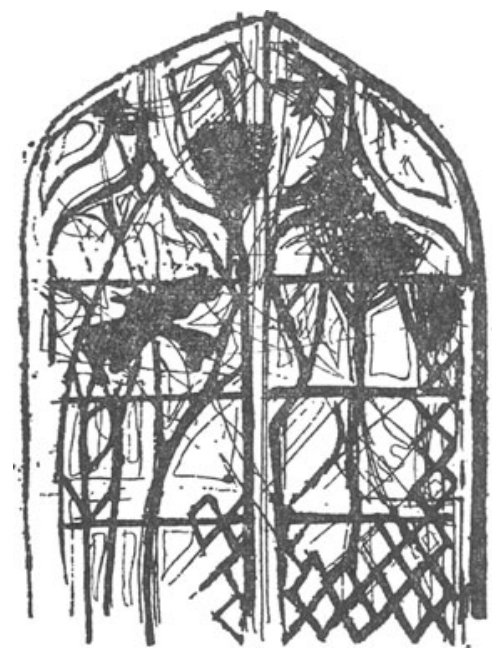

\title{
AFTERNOON SERVICE AT MELLSTOCK
}

\section{Circa 1850}

ON afternoons of drowsy calm

We stood in the panelled pew,

Singing one-voiced a Tate-and-Brady psalm

To the tune of 'Cambridge New.'

We watched the elms, we watched the rooks,

The clouds upon the breeze,

Between the whiles of glancing at our books,

And swaying like the trees.

So mindless were those outpourings! -

Though I am not aware

That I have gained by subtle thought on things

Since we stood psalming there. 